\title{
PROMOTING CLIENT PARTICIPATION: A STUDY OF YOUTH PROBATIONERS IN HONG KONG
}

The concept of 'client participation' has been popular in social work since the 1970s. In view of the increased discussion on user-led practice in social work, it is not surprising to see that the concept of client participation has surged to a position of prominence in the professional discourse of social workers. Generally speaking, most social workers agree that encouraging clients' involvement in the helping process is valuable. The practicality of this concept deserves further exploration, especial in the area of young offenders since they are usually perceived as immature, having low self-esteem, lack of coping ability and self-control (Jessor et al., 1991; McWhirter et al., 1998).

In order to investigate this issue, an exploratory study was conducted in Hong Kong's probation service. This paper reports on a qualitative study that was carried out in all 13 district probation offices in the territory. Although differences exist in the training of probation officers (POs) and social workers, there are also many similarities. In Hong Kong, a degree in social work is the basic qualification for probation officers. Normally after an intensive four-month induction programme supervised by the trainers (senior POs), probation trainees are assessed to be qualified. Then, they can be gazetted as POs.

As background for this study, the Hong Kong Probation Service is described in the next section. This is followed by a description of the characteristics of youth probationers in Hong Kong. Conceptions of ‘client participation' are given before the present study is introduced. 


\section{Probation Service}

Hong Kong’s probation service was established in 1933 to ‘advise, assist and be-friend' offenders for the purpose of rehabilitation (Hong Kong Government, 1934). The basic principle of the service is:

...that the offender can be best rehabilitated within the community with suitable professional intervention and support for the offenders and their families. Residential training or custodial treatment is necessary for a minority of offenders when no community-based treatment option is suitable (Social Welfare Department, 1999: 75).

The specific objectives of the service are:

(i) To prepare social inquiry reports on offenders' background as requested by the courts and on long-term and petitioning prisoners for reviewing of their sentences.

(ii) To provide supervision and guidance to offenders placed on probation for a period specified under a probation order.

(Social Welfare Department, 1999: 75).

Hong Kong's probation service is an executive arm of the courts that employs a community-based intervention alternative. It uses a social work approach to provide supervision and guidance to offenders for a specified period of time in order to achieve a rehabilitation.

\section{Characteristics of Youth Probationers (YPs)}

Young offenders who have encountered various problems, such as physical and sexual abuse, suicide, gang membership, substance abuse, homelessness and dropping out of school are considered to be 'high-risk' youth (Capuzzi and Gross, 1996). A multitude of unfavourable traits has been suggested as characteristics of high-risk youth. These include low resiliency, low self-esteem, lack of communication skills, 
inability to cope with stress, lack of self-control ability and lack of purpose in life (Cohen, 1986; Pitts, 1990; Jessor et al., 1991; McWhirter et al., 1998; Muncie, 1999; Wong, 1999). Some indigenous qualitative studies on YPs in Hong Kong (Cheng, 1990; Tam, 1991; Kiang, 1992; Wong, 1992; Chow, 1998; Lau, 2000) revealed that they share an anti-social subculture, are subject to undesirable influence from the peers, lack family care and have weak bonds with school/work. Membership in Triad gangs is also common among these young people and hence they share in a Triad subculture. Thus, it is evident that the ability young probationers to understand their problems and suggest ways to solve them is jeopardized by the problems they face and the characteristics they share. This leads to further skepticism about the ability of YPs to 'participate' in the helping process initiated by POs for their rehabilitation.

\section{Conceptions about Client Participation}

Promotion of client participation is a trend that has had considerable influence on social work practice. Most social workers acknowledge the value of promoting clients' involvement in the helping process. The following three issues have strongly influenced the development of the client participation concept and its subsequent promotion in the field of social work.

Awareness of Client Participation Rights: A document from the British Association of Social Workers (BASW, 1980) indicates that the concept of client participation was already widespread in all social work activities in the United Kingdom from the late 1970s. In the United States, the NASW Code of Ethics also states that the 'social worker should make every effort to foster maximum self-determination on the part of 
clients' (NASW, 1993: 1). The 'Prometheus Principle' was recommended as a governing principle for client participation (Fischer and Brodsky, 1978). The principle states that 'knowledge, power and responsibility should be shared by all parties engaged in offering human services with those receiving such services' (Fischer and Brodsky, 1978: ix). This growing importance of client participation indicates that the helping process of social work is evolving from an autocratic system with professionals holding power to a more democratic system with clients in full partnership with professionals.

A growing awareness of the rights of service users (clients) to participate in the helping process and of the responsibility of social workers to make every effort to foster maximum participation of service users is evident in codes and principles promulgated in the UK and the USA.

Promotion of Clients’ Empowerment: The trend toward client empowerment has also significantly influenced the promotion of client participation. Empowerment is defined as 'the means by which individuals, groups and communities become able to take control of their circumstances and achieve their own goals, thereby being able to work towards helping themselves and others to maximize the quality of their lives' (Adams, 1996: 5). Brohman (1996) articulated the relationship between empowerment and client participation by suggesting that 'the concept of participation as empowerment comes close to the notion of development as fulfillment of human potentials and capabilities’ (Brohman, 1996: 265). Croft and Beresford (1994) pointed out that the aim of partnership and participation is to empower people. Therefore, to promote client participation is an empowerment process through which people are offered opportunities to take control of their circumstances and to develop their potentials and capabilities in order to attain positive self-development. 
Emphasis on Consumerism: Parallel to the development of the client participation and empowerment movement is the concept of consumerism. It has also been a prevailing concept in social services. Under the influence of the business sector idea of 'total quality management', social service agencies are adopting the language of consumerism. They are talking about hearing the voice of the consumer and focusing on customers’ needs (Martin, 1993; Gunther and Hawkins, 1996; Skelcher, 1996). Fundamentally, the doctrine of consumerism within human service systems is that 'individuals are more knowledgeable about their own needs and interests than professionals. When individuals redefine their role from that of client to that of consumer, their sense of control over their lives is elevated' (Tower, 1994: 192).

\section{$\underline{\text { Kinds of Client Participation }}$}

Parsloe (1990) defined two aspects of client participation, namely, expressive and developmental. The expressive aspect is much more ideological, representing a belief that 'people have a right to have a say in the services they receive'. The developmental aspect represents 'a means of achieving greater individual fulfillment, personal development, self-awareness and some immediate satisfaction’. From her study, she concluded that social work professionalism does not prohibit the enhancement of client participation rather professionals should promote the clients' right to choose the social work methods they receive. These two aspects of participation were used as the framework for recommendations based on the study.

\section{The Study (Note 1)}

This paper reports on a qualitative study conducted in Hong Kong's probation service. Data for this study were collected through in-depth interviews with an 
interview schedule that included 15 POs, 7 male and 8 female, randomly selected from the 13 district offices in the territory. The interview schedule was constructed mainly to explore the officers' understanding of the conceptions of client participation, to judge their support for the concept, and to observe how they actually practise the concept in the service delivery process. In order to increase the richness of the information and data collected, one of the criteria for the selection of POs be interviewed was that they should have worked in the service as gazetted officers for at least two years. Another criterion for their selection was that they had to have experience in supervising youth probationers (YPs). Ten of the officers interviewed had been working in the service for two to three years, 3 had been working in the service for three to four years and 2 had been working in the service for over four years. All of them were trained (registered) social workers in Hong Kong. To preserve anonymity, PO respondents were assigned a serial code from PO1 to PO15. Twenty-eight YPs aged 14-20 (Note 2), 21 male and 7 female, were also randomly selected and successfully interviewed using another interview schedule. This interview schedule was constructed mainly to explore their understanding of the conceptions of 'client participation' and to evaluate how they were actually involved/participated in the supervision process. In order to obtain YP respondents with adequate experience to share, one selection criterion was that they had to have served their respective orders for at least half of the period. Eleven YP respondents had served their Supervision Orders/Probation Orders for 12 months, 1 for 15 months, 15 for 18 months and 1 for 24 months. Again, to preserve anonymity, YP respondents were assigned a serial code from YP1 to YP28. The fieldwork part of the study was conducted from November 1999 to March 2000. 


\section{Promotion of Client Participation in Working with Youth Probationers: Probation Officers’ Responses}

\section{$\underline{\text { POs’ Understanding of Client Participation }}$}

In response to a question exploring their understanding of the concept 'client participation' in the supervision process of YPs, all POs indicated that they understood the concept although they described it in different terms. They shared similar ideas about client participation as a way to maximize clients' commitment to decision making and to plans for action in the helping process. Examples include:

I heard this term in my university training. This concept is similar to self-determination in social work. Clients need to be involved in defining their problems and needs. Clients should design their own plans for solving their problems. When clients realize their problems and needs, they are more motivated to take action to solve their problems. (PO1) Client participation is a concept referring to the need to involve clients in defining their problems and needs. When they realise their needs and problems, their commitment to take action to solve their problems can be reinforced. (PO9)

Seven POs (PO1, PO3, PO4, PO7, PO10, PO12 and PO15) highlighted that client participation as a conception generated from a respect for self-determination. This is similar to Carroll's idea (1980). Most PO respondents (PO1, PO2, PO3, PO4, PO5, PO6, PO7, PO10, PO11 and PO15) opined that the concept 'client participation' is applicable to the work of probation service.

While the respondents had similar ideas on client participation, they focused on different concerns. Three respondents (PO1, PO10 and PO15) saw client 
participation as a client's basic right (expressive aspect). Three (PO2, PO5 and PO6) expressed a continuing interest in clients' growth after their involvement with the clients in the supervision process (developmental aspect). Three respondents (PO3, PO4 and PO11) were concerned with both the expressive and the developmental aspects of client participation (Parsloe, 1990).

\section{$\underline{\text { POs’ Actual Practise in Promoting Client Participation }}$}

Since most POs supported the promotion of client participation in working with YPs, we explored their strategies for promoting client participation in the supervision process with their YPs. POs' supervision of YPs can be classified into three phases: Initial (first two months of the Order), Intermediate (the third month till two months before completing the Order) and Ending (the last two months of the Order).

\section{(1) Initial Phase}

There is more evidence that PO's support the promotion of client participation during the Initial supervision phase of their work with YPs. Findings revealed that most POs agreed about the importance of sharing service objectives with the YPs. POs also regarded it as fundamental that YPs know the roles of POs in order to promote client participation. At the Initial phase, most POs commonly explain the service objectives of probation and clarify their role as a PO to their YPs. Most of them reported that they provide YPs with a brief introduction of the service and of their role as a PO. Two respondents said,

I directly tell youth probationers the purpose of the Orders they received and of my role as their PO. (PO3)

I tell the probationers the objectives of the service and how I will help them achieve the objectives. (PO10) 
POs frequently involved YPs to discuss their problems and needs during the Initial supervision phase. Some PO respondents reported that they encourage YPs to talk about their problems and to think about the causes of their problems. Two examples are:

In order to encourage them to think about their problems and needs, I talk to them about the reasons why they think they were placed in probation. I also encourage them to talk about their needs. (PO3)

I ask YPs to talk about the causes of their problems at the beginning of the supervision period, because it is important for them to understand the causes in order to help them realize their needs. (PO9)

However POs did not generally inform YPs that they keep records of their probationers. Some POs said that the practice of informing YPs about their records was redundant since most probationers know that their records are kept in the offices.

It is not necessary to tell YPs that their records are kept in our office. From the day they are sentenced to serve a probation order, they know that such document exist. (PO7)

You don't need to tell them that you have kept records on them, they already know. (PO9)

Only 2 POs reported that during the Initial phase they tell YPs their rights as clients. However, the contents of this kind of conversation were usually limited to informing YPs of their rights to give feedback to POs on their feelings of the helpfulness of the officers. The 2 POs gave similar statements:

I tell the YPs that they have the right to tell me whether my work with them is helpful or not. (PO1)

I tell YPs that one of their rights is that they can feel free to give me 
feedback on the effectiveness of my work with them. (PO12)

It is noted that most POs tell YPs about their obligations under Supervision Orders/Probation Orders.

I inform them about their obligations as stated in the Orders such as informing me about a change of address or work place. (PO3)

I stress the importance of meeting their obligations as stated in the Orders. They need to inform me about a change of school or work, they need to observe the night curfew, and they need to inform me if they move to another place. (PO6)

We need to remind them about their obligations under probation such as observing the night curfew, informing me for a change of address or change of school or job. (PO10)

\section{(2) Intermediate Phase}

Some POs involve YPs in an assessment of their needs early in the Intermediate phase in supervision order. They consider YPs more knowledgeable about their needs even though they know that the needs won't necessarily be easy to satisfy. Two PO respondents had the following remarks:

I think that as young people, the YPs are more knowledgeable about their needs. I ask them what they see as their needs and what I can do to help satisfy their needs. (PO4)

Even though their needs aren't easy to fufill, I ask them to tell me about them. I also ask them to assess the feasibility of satisfying them. (PO8) In the Intermediate phase, a few POs reported that they encourage the YPs' active involvement in the assessment process. The following responses from 2 POs revealed some common difficulties faced in supervising YPs at this stage. 
They don't trust us. I can feel their resistance to discussing their life experience with me. It is difficult for me to share my assessment with them and to motivate them to improve their behaviors. (PO3) I have tried to invite some YPs to have a discussion about their assessment of their action plans. They broke the appointments several times. With a heavy caseload, I cannot afford to wait for them to participate in the assessment so I finished the assessments by myself. (PO11)

\section{(3) Ending Phase}

All POs recognized the importance of the Ending phase in the supervision process. Most of them considered the termination of the Order as an appropriate time to consolidate their work with the YPs and to help them identify their strengths, recognize their growth and build up their confidence to face their future. An emphasis on the developmental aspect of client participation was evident. However all of them also mentioned that the YPs were more conscious of the termination than they were. Although they tried to employ different methods (e.g. questionnaires, review sheets, story-telling) to help YPs consolidate their experience at the Ending phase, they felt that YPs 'tuned them out'. They were only interested in finishing the

Orders. This contradictory phenomenon is illustrated in the following responses: I believe that when we appraise YPs' effort and growth in the supervision process, the resulting consolidation gives them the feeling of being respected. However, they have neither the mind and nor the heart to listen to you near the end of their Orders. All they want is to finish the Orders as soon as possible. (PO10)

Helping YPs to consolidate their experience in the supervision process can enhance their awareness of their strengths and can help them find out their 
readiness to deal with their problems independently in the future. But most YPs just want the Orders to end. They don't want to see you anymore. (PO15)

The findings show that most respondents treated termination as an important phase in their supervision work with YPs. However, they focused more on the YPs' growth (developmental participation) when they helped them consolidate their experience.

In concluding the two sections on POs' beliefs about client participation and their actual practise, it seems that POs' beliefs about client participation were inconsistent with their actual practise in the supervision process of YPs. Although they generally agreed that client participation is a way to maximize clients' commitment in decision making and action plans in the helping process, there was a lack of evidence that their ideas were actualised. They placed greater emphasis on the YPs' obligations than on their rights under probation orders. Although they were more willing to involve YPs in identifying their problems and needs, POs were not as strongly driven to involve YPs in the process of formulating assessment and intervention plans. They tended to focus more on their own personal judgement in implementing their plans.

POs' Perceptions of the Feasibility of Promoting Client Participation in Working with YPs

POs were asked about their opinions on the feasibility of promoting client participation during the process of supervising YPs. The evidence suggests that they had not seriously thought about the idea of promoting client participation. They tended to confuse the idea of client participation with that of self-determination. Three typical responses were:

I think I have promoted client participation in my work with YPs because I always encourage them to make decision for themselves. (PO2) 
I think client participation is similar to self-determination in social work. Although the courts sentenced YPs to serve a period of probation, we still emphasize that in the supervision process they need to make decision for themselves. (PO8)

I usually encourage YPs to make decision about their action. They have to be responsible for their behavior. I fully respect their right to self-determination even though their behavior might cause them trouble. I believe that this is an actualisation of client participation. (PO14)

The above responses show that POs tend to confuse the idea of client participation with that of self-determination. Moreover, the idea of client participation is more a human service philosophy while the right to self-determination is more a social work working principle.

\section{Difficulties Encountered by POs in Promoting Client Participation}

When asked what difficulties they encountered when promoting client participation in probation service with YPs, POs gave responses that can be summarised as: 'YPs lack of trust', 'heavy workload' and 'attributes of YPs'. The following responses are representative:

I find it difficult to encourage YPs to assess their needs because they do not trust us. They actually think that we are trying to find fault with them. (PO4)

With an average of 50 cases to supervise and 10 Social Enquiry Reports to complete per month, it is difficult for me to squeeze in the time to spend much of it on the YPs. As long as they follow the Orders and they're not 
re-convict, they'll be alright. Allowing them to participate in the supervision process is too labor intensive for me. (PO11)

YPs are quite impulsive in their behavior. Even if they've decided to behave well, the environment, that is their peers, plays an important part. With their weak self-control and immaturity, I don't think allowing them to make decision for themselves works. (PO15)

\section{Promotion of Client Participation in Working with Youth Probationers: Youth Probationers' Responses}

\section{$\underline{\text { YPs’ Understanding of Client Participation }}$}

After introducing the concept of client participation to youth probationer respondents during the interviews, it was found that most understood the meaning of the concept in terms of joining in activities. However, their knowledge of client participation in terms of the supervision process was vague. All of them said that they had never heard the term from their POs. Altogether, 20 respondents (YP1, YP2, YP3, YP4, YP5, YP6, YP7, YP8, YP9, YP10, YP11, YP14, YP15, YP16, YP17, YP19, YP20, YP21, YP23 and YP25) defined client participation as 'joining activities', 5 respondents (YP12, YP13, YP26, YP27 and YP28) expressed the term directly as 'being involved' and only 3 respondents (YP18, YP22 and YP24) interpreted it as 'having a say and choices in the supervision process and making decisions jointly with the PO'.

\section{$\underline{\text { YPs' Participation in the Supervision Process }}$}

To further explore the perceptions of the YP respondents and their participation 
in the supervision process, a checklist presenting some practical ideas of ways client participation is implemented was presented to help them review their experience. YP respondents were asked to score each item. The results are shown in the Table 1.

(Insert Table 1 about here)

It is interesting to note that in Table 1 the YP respondents scored 'Having A Say in the Setting of Working Goals in the Supervision Process' highest, suggesting that they strongly felt it. However, 'Being Informed about their Rights and Obligations' (as probationers) scored the lowest. Further review of the data revealed that most YPs considered that their POs performed well in informing them about their obligations but poorly in informing them about their rights as probationers. Relatively more YPs (7) were not satisfied with their 'Accessibility to their Personal Records'.

Even though the findings indicate that POs were given above average scores overall for their promotion of client participation, from the comments of the YP respondents the actual practise of client participation promotion by POs was less successful. When invited, most YP respondents were unable to give examples of how their POs requested their participation in the supervision process. They found it especially difficult to find examples of ways they were informed about their rights as probationers and their accessibility to their personal records. It is significant to note that even though the YPs were unable to quote many examples of their actual participation in the supervision process, as reflected from the scores, most of them did feel that they were able to participate in the supervision process without many constraints. This inconsistency suggests that there was something much more important than actual client participation practise, that is, the attitude of the POs in 
inviting the YPs to be involved in the supervision process. Although most YPs could not recall actual examples of their participation in the supervision process, they did feel their workers were willing to share and accept their opinions and behaviors.

Over half of the YP respondents (18) reported that they could voice their opinions to their POs without hesitation since the POs were open and willing to respect different viewpoints. Some respondents said that their POs openly invited them to talk about their problems. Two examples are as follows:

My PO is willing to listen to my problems. I don't know, not like other officers I heard of, she never judged my behaviors as wrong. She just pointed out to me the possible negative consequences of my behaviors. (YP5)

He (PO) will invite me to talk about my experience in school and ask if there are problems. He seldom condemns me for my misbehaviors, but just tells me that if I do it again I may run the risk of breaching the Order. (YP25)

Most YP respondents were able to cite many examples of their being invited to discuss and assess the problems they encountered during the Initial supervision phase. They were also invited to voice their needs in the early supervision stage. But concerning plans needed to solve their problems, they felt that they had little say in the decisions made. They reported that the POs decided on the plans. The followings are three examples from the YPs:

I have little say about my study plan. My PO said that I need to find a school and resume schooling. If I don't do that, then I'm breaching the Order. (YP4)

After listening to my own assessment of my problems, my PO said that I 
need to find a job to keep myself busy so that I won't have time to associate with my peers and do bad things. He said that this is also a requirement of the Order. (YP15)

My PO said that I need to live with my aunt (mother's sister) who can give me more attention. I need to find a job for myself and live an industrious life. (YP22)

The YPs did not mention many examples of their involvement in the decision making process at the later supervision phases (Intermediate and Ending). Most of them stated that they mainly reported their daily activities to their POs in their meetings. Below is an example:

From the fourth month onwards, most of our meetings were for reporting my daily activities. It is probably concerned about finding out if I have breached the Order. (YP8)

It is interesting to note that most YPs were conscious of the date on which their Orders would end. Since most of them were near the completion date of their Orders, they were not concerned about whether or not their POs would help them consolidate their experience in the supervision process. They just looked forward to the end of their probation. Comments from 2 YPs reflect this attitude:

I just want to finish serving this Order as soon as possible. I want to be free and do what I want. (YP12)

When this Order ends, I will have my freedom again and make my plans happen. (YP27)

It is noted that most YP respondents stated that they had confidence that they would be able to refrain from committing further acts of delinquency and that they 
would be independent after completing the Orders. They felt confident facing the future.

\section{Promotion of Client Participation in Working with Youth Probationers:}

\section{The How}

Although POs have raised reservations about promoting the concept of client participation in the work with YPs, because they are perceived as immature, lacking of self-confidence and low in ability, the findings of this study indicate that promoting the concept has some strengths. If implemented strategically, client participation can yield fruitful result during the supervision process of YPs. Most of the interviewed POs had, to varying degrees, attempted to apply the concept of client participation in supervising YPs. However, it seems that POs placed greater emphasis on the developmental aspect of participation than on the expressive aspect (Parsloe 1990). Although POs intended to implement the practise of client participation in supervising YPs, they did not apply it consciously and systematically enough. Based on analysis of the findings, some principles were developed to assist POs in the practise of promoting client participation of YPs for both the expressive and the developmental aspects of participation in probation service. These principles were developed with reference to both the phases of work and related work focuses in probation service.

\section{Principles of Promoting Client Participation in Supervising YPs}

The work of supervising YPs during the Initial Phase focused on two areas for clarification: (1) The purpose of the probation service clarified for the YPs, and (2) 
The roles of the PO is clarified.

(1) In order to clarify the purpose of the probation service for the YPs, the following principles are suggested:

\section{Principles for Promoting Clients’ (YPs’) Expressive Participation:}

1. PO should provide YPs with a clear description of the purpose, objectives and mode of service delivery of the service.

2. POs should ensure that YPs have an adequate understanding of the possible consequences of receiving probation services.

\section{Principles for Promoting Clients’'(YPs') Developmental Participation:}

1. POs should recognize YPs as experts on their own situation.

2. POs should have expertise in the process of professional intervention.

(2) In order to clarify the roles of the PO, the following principles are suggested:

\section{Principles for Promoting Clients’ (YPs') Expressive Participation:}

1 POs should clearly discuss their roles and responsibilities in the supervision process with YPs.

2 POs should clearly tell YPs that they have the right to be treated with respect and dignity by POs and that POs will maximize their confidentiality and self-determination.

Principles for Promoting Clients’ (YPs') Developmental Participation:

1. POs should stress that the supervision process is a collaborative partnership between POs and YPs.

2. POs should promote YPs' active participation and self-determination in all aspects of the change effort. 
In the Intermediate Phase, the main work focuses on: (1) Problem/Need assessment, (2) Formulation of an intervention plan, and (3) Involvement in the intervention.

(1) The following principles are suggested for POs to assess the needs/problems of YPs:

Principles for Promoting Clients’'(YPs’) Expressive Participation:

1. POs should maximize the opportunities YPs have to obtain clear and accurate information about POs' assessment of their needs and problems.

2. POs should involve YPs in gathering and analyzing information for assessing and meeting their needs.

Principle for Promoting Clients’ (YPs') Developmental Participation:

1. POs should involve YPs in examining and assessing their problems.

(2) The following principles are suggested to aid POs in involving YPs in the formulation of their intervention plan:

Principles for Promoting Clients' (YPs') Expressive Participation:

1. POs should involve YPs in setting their working goals.

2. POs should obtain consent from YPs for every action in the supervision process.

Principles for Promoting Clients' (YPs') Developmental Participation:

1. POs should incorporate the YPs' strengths into the intervention process.

2. POs should involve YPs in exploring and analyzing available resources.

3. POs should help YPs clarify and operationalise their chosen working 
goals so as they can formulate action plans.

(3) The following principles are suggested to increase the involvement of YPs in the intervention:

\section{Principles for Promoting Clients’ (YPs') Expressive Participation:}

1. YPs have the right to choose various alternative interventions.

2. YPs have the freedom to express their opinions, ask questions, make choices, and work together with POs.

Principles for Promoting Clients’ (YPs') Developmental Participation:

1. POs should encourage YPs to identify and express their thoughts and feelings about carrying out action plans.

2. POs should support the effort of YPs to build productive and empowering connections with others.

3. POs should explore and create new resources that will facilitate the empowerment of YPs in their social and physical environments and will enhance their sense of mastery.

4. POs should use case records to assess and empower YPs.

The work of supervising YPs during the Ending Phase focuses on: (1) Consolidation work, and (2) Evaluation and feedback.

(1) The following principles are suggested to consolidate work with YPs:

Principle for Promoting Clients' (YPs') Expressive Participation:

1. POs should help YPs to reflect on and learn from their experience in the whole supervision process.

Principle for Promoting Clients’(YPs') Developmental Participation:

1. POs should conclude the helping process by celebrating the success of YPs, stabilizing their positive changes and encouraging them to 
function independently.

(2) The following principles are suggested for POs to involve YPs in the evaluation process and to encourage them to give feedback:

\section{Principles for Promoting Clients’'(YPs') Expressive Participation:}

1. YPs should be involved in the evaluation process.

2. YPs' opinions on service provision and POs' performance should be collected.

3. YPs have the right to know the channels to give feedback and to make complaints.

\section{Principles for Promoting Clients’ (YPs’) Developmental Participation:}

1. POs should work with YPs to identify methods and strategies that they have used most effectively.

2. POs should empower YPs with knowledge that may be useful to them in meeting future challenges.

These principles can also be applied to other individual guidance work settings. Internalizing these principles can help POs systematically apply client participation in their practise and increase their awareness of how to involve YPs in the supervision process. Similarly, they ought to be incorporated into the service policy to guide quality practise.

Furthermore, there are two implications for the work of POs with YPs that influence the promotion of client participation:

\section{Cultivating PO’s Faith in Client Participation}

It is observed that the most crucial factor to the promotion of client participation in the supervision process was not the nature of YPs, the workload, or even the 
service policy, but the PO himself/herself. No matter what phase of the supervision process, YPs were able to take an active role if their POs allowed them to do so. It follows that POs' belief in the advantages of promoting client participation in the supervision process with the YPs was the crucial factor. Although YPs may not have had a clear understanding of the concepts of client participation, they judged their POs' respect and acceptance as crucial elements in the helping relationship. As the idea of implementing client participation by POs was shown to have positive effects on YPs in the helping process, cultivation of this faith in POs is imperative.

\section{Developing Strategies for Promoting Client Participation}

It was shown that most POs only provided their YPs with a brief introductions to the service and to their roles in the Initial supervision phase. In the Intermediate supervision phase, POs did not show a strong sense of the importance of involving YPs in the formulation of an assessment and intervention plan in order to safeguard their rights (expressive participation) and enhance changes and learning (developmental participation). In fact, YPs could be trained to make decisions on personal matters if POs developed some strategies for maximizing their opportunities to participate. As POs' knowledge and experience in client participation are less than adequate, besides observing the principles discussed above, developing strategies for promoting such practices is a priority.

\section{Conclusion}

This study attempted to explore the applicability of the concept of 'client participation' in probation service with youth probationers who are often judged as immature, lacking of confidence and low in ability. 
The findings of this study revealed that although they describe it in different terms, POs had some basic understanding of the concept of client participation. In the supervision process, they clarified their roles at the Initial Phase. However, they were not conscious of the need to involve YPs in the assessment and intervention process in the Intermediate Phase. Even though they attempted to promote the practice of client participation with their YPs, they did not apply it systematically. POs treated the conclusion of the probation as an important phase for assisting YPs to reflect on their growth (developmental participation) by helping them to consolidate their learning from the helping experience. Although YPs might lack the motivation to evaluate their growth, the enthusiasm of POs to lead them in an assessment should not be diminished.

The findings of this study showed that YPs had vague knowledge of the concept of client participation. Nevertheless, they graded their participation in the supervision process as favorable (Table 1). It was found that even in the Initial Phase, they were ready to know more about their rights though they were seldom given information about them. They were asked to and were willing to share their problems and needs with POs. But it was also observed that YPs' had little say about the working plans they needed to follow under the Orders. They were also conscious about the completion of the Orders. As a whole, most YP respondents reported that they had confidence in themselves that they would never again commit a crime.

Based on an analysis of the findings of this study two sets of working principles are proposed. The first concerns the promotion of clients' expressive participation and the second concerns the promotion of clients' developmental participation. Furthermore, policies should be pursued that cultivate POs' faith in client 
participation and that develop strategies for its promotion in work with YPs.

This study revealed that success is not just determined by the POs' good will, genuineness, sensible advise, concern and the availability of resources. The provision of opportunities for the active participation of YPs, such as expressing opinions, asking questions, making choices, sharing information and working together in the helping process, is also important. One significant conclusion of this study is that, despite common skepticism, client participation can be promoted in work with YPs who might otherwise be judged as immature, lacking confidence and low in ability. 


\section{Endnotes}

(1) This study was funded by the Committee on Research and Conference Grants of the University of Hong Kong. The author also wishes to acknowledge the support from the Social Welfare Department of the Hong Kong Special Administrative Region of China in this study.

(2) According to the Juvenile Offenders Ordinance (Chapter 226) of Hong Kong, a 'young person' is defined as '14 years of age or upwards and under the age of 16 years'. But the Hong Kong Police Force defines a 'young person' as from 16 to 20 years of age. As a compromise, 'youth probationers' were defined as those aged 14 to 20 . 


\section{Author's Notes}

Francis Wing-lin Lee is an Assistant Professor in the Department of Social Work and Social Administration in the University of Hong Kong. He received his Ph.D. in Criminology from the University of Hull, UK in 1992. He has been involving in social work education in Hong Kong for over fourteen years. His areas of specialty and research interest include groupwork with young people, individual work and groupwork with 'youth-at-risk' and young offenders, youth services, causes of juvenile delinquency, treatment programmes for young offenders, policing and criminology. He is currently a member of the British Society of Criminology and Hong Kong Society of Criminology, an associate fellow of the Youth Studies Net (YSNet) of the City University of Hong Kong, a fellow of the Centre for Criminology of the University of Hong Kong and a registered social work in Hong Kong. His recent publications include:

1. "The Possibility of Promoting User Participation in Working with High Risk Youth" British Journal of Social Work. (2002) Vol.32 (in press).

2. Encounters Between Police and 'Unattached Youth' and the Occurrence of Juvenile Delinquency” Police Practice and Research: An International Journal. (2002) Vol.3 (in press).

3. "Working with Natural Groups of Youth-at-risk: An RGC Approach” Groupwork. (2000) Vol.12(3):21-36.

This study was funded by the Committee on Research and Conference Grants of the University of Hong Kong. The author also wishes to acknowledge the support from the Social Welfare Department of the Hong Kong Special Administrative Region of China in this study.

\section{Address for Correspondence:}

Department of Social Work and Social Administration

The University of Hong Kong

Pokfulam

Hong Kong

(852)2857-8569 (Tel.)

(852)2858-7604 (Fax)

fwllee@hkucc.hku.hk (E-mail) 


\section{References}

Adams, R. (1996) Social Work and Empowerment. London: Macmillan Press Limited.

Atkinson, J.M. and Elliott, L. (1994) 'Evaluations and Consumers’, in: M. Titterton (Ed.), Caring for People in the Community: The New Welfare. 153-67, London: Jessica Kingsley Publishers.

British Association of Social Workers (1980) Clients are Fellow Citizens: Report of the Working Party on Client Participation in Social Work. Birmingham: BASW.

Brohman, J. (1996) Popular Development: Rethinking the Theory and Practice of Development. Cambridge, Mass.: Blackwell Publishers Inc.

Capuzzi, D. and Gross, D.G. (Eds.) (1996) Youth At Risk: A Prevention Resource for

Counselors, Teachers, and Parents. $2^{\text {nd }}$ ed., Alexandria, VA: American Counseling Association.

Carroll, M (1980) 'Collaboration with Social Work Clients: A Review of the Literature’, Child Welfare. LIX(7), 407-17.

Cheng, T.Y.T. (1990) A Study of the Practice of the Probation Officer in the Delivery of Services to Juvenile Probationers in Hong Kong. (unpublished M.S.W.

Dissertation), Hong Kong: The University of Hong Kong.

Chow, M.Y.R. (1998) The Impacts of the Probation Service on Young Probationers' Delinquency Cessation. (unpublished M.Soc.Sc. Dissertation), Hong Kong: The University of Hong Kong.

Cohen, P. (1986) Re-thinking the Youth Question. (Post-16 Education Centre Working Paper No. 3), London: Institute of Education. 
Croft, S. and Beresford, P. (1994) ‘A Participatory Approach to Social Work’, in:

C. Hanvey, and T. Philpot (Eds.), Practising Social Work. 49-66, London: Routledge.

Fischer, C.T. and Brodsky, S.L. (1978) Client Participation in Human Services: The Prometheus Principle. New Jersey: Transaction Books.

Gunther, J. and Hawkins, F. (1996) Total Quality Management in Human Service Organizations. New York: Springer Publications.

Hong Kong Government (1934) Hong Kong 1933. Hong Kong: Government Printer. Jessor, R.; Donovan, J.E. and Costa, F.M. (1991) Beyond Adolescence: Problem Behavior, and Young Adult Development. New York: Cambridge University Press.

Kiang, K.L. (1992) An Exploratory Study on the Juvenile Probationers in Hong Kong: The changes in Life Situation and their Reaction. (unpublished M.S.W. Dissertation), Hong Kong: The University of Hong Kong.

Lau, T.K. (2000) The Implications of Delinquent Subculture on Working with Young Probationers. (unpublished M.Soc.Sc. Dissertation), Hong Kong: The University of Hong Kong.

Martin, L. (1993) Total Quality Management in Human Service Organizations. California: Sage Publications.

McWhirter, J.J.; McWhirter, B.T.; McWhirter, A.M. and McWhirter, E.H. (1998) At-Risk Youth: A Comprehensive Response - For Counselors, Teachers, Psychologists, and Human Service Professionals. London: Brook/Cole Publishing Company.

Muncie, J. (1999) Youth and Crime: A Critical Introduction. London: Sage. 
National Association of Social Workers (1993) NASW Code of Ethics. Washington, DC: NASW.

Parsloe, P. (1990) A New Role for Clients in Social Welfare: Partnership, Participation, Consumerism and Decentralization. (Occasional Paper Series No. 1), Hong Kong: Department of Social Work, Hong Kong Baptist College. Pitts, J. (1990) Working with Young Offenders. London: MacMillan Education Ltd.

Skelcher, C. (1996) 'Public Service Consumerism: Some Questions of Strategy’, Community Development Journal. 31(1), 66-72.

Social Welfare Department (1999) The Five Year Plan for Social Welfare Development in Hong Kong - Review 1998. Hong Kong: Government Printer. Tam, K.P. (1991) An Exploratory Study of Transition from School to Work of Juvenile Probationers. (unpublished M.S.W. Dissertation), Hong Kong: The University of Hong Kong.

Tower, K.D. (1994) 'Consumer-centred Social Work Practice: Restoring Client Self-determination', Social Work. 39(2), 191-96.

Wong, D.S.W. (1999) An Exploration of Young People's Value Systems and Deviant Behavior. (in Chinese), Hong Kong: Joint Publishing (H.K.) Co., Ltd.

Wong, Y.Y. (1992) A Study of Young Probationers' World of Work: Implications for Social Services. (unpublished M.S.W. Dissertation), Hong Kong: The University of Hong Kong. 
TABLE 1

YP Respondents' Grading of their Participation in the Supervision Process

\begin{tabular}{|c|c|c|c|c|c|c|c|c|}
\hline \multirow[t]{2}{*}{ Case } & \multicolumn{2}{|c|}{ "Being Informed } & \multirow[t]{2}{*}{$\begin{array}{l}\text { Making Decisions } \\
\text { Jointly }\end{array}$} & \multicolumn{2}{|c|}{$\begin{array}{l}\text { Accessibility to } \\
\text { Information }\end{array}$} & \multicolumn{3}{|c|}{$\begin{array}{l}\text { Having A Say in the } \\
\text { Supervision Process }\end{array}$} \\
\hline & A & B & & $\mathrm{C}$ & $\mathrm{D}$ & $\mathrm{E}$ & $\mathrm{F}$ & G \\
\hline YP1 & 4 & 3 & 2 & 4 & 5 & 3 & 4 & 4 \\
\hline YP2 & 3 & 3 & 2 & 4 & 3 & 4 & 3 & 3 \\
\hline YP3 & 4 & 5 & 4 & 4 & 5 & 5 & 5 & 5 \\
\hline YP4 & 3 & 2 & 4 & 2 & 4 & 4 & 3 & 4 \\
\hline YP5 & 3 & 2 & 4 & 5 & 3 & 4 & 5 & 3 \\
\hline YP6 & 5 & 3 & 4 & 2 & 3 & 4 & 4 & 3 \\
\hline YP7 & 5 & 5 & 4 & 5 & 5 & 3 & 5 & 5 \\
\hline YP8 & 2 & 3 & 4 & 5 & 2 & 4 & 5 & 3 \\
\hline YP9 & 2 & 3 & 4 & 5 & 5 & 3 & 3 & 3 \\
\hline YP10 & 4 & 2 & 2 & 3 & 3 & 4 & 2 & 4 \\
\hline YP11 & 3 & 4 & 2 & 3 & 3 & 2 & 4 & 3 \\
\hline YP12 & 4 & 4 & 3 & 3 & 4 & 3 & 4 & 4 \\
\hline YP13 & 4 & 3 & 4 & 5 & 2 & 3 & 5 & 3 \\
\hline YP14 & 4 & 3 & 4 & 3 & 3 & 3 & 3 & 2 \\
\hline YP15 & 4 & 4 & 4 & 3 & 4 & 4 & 5 & 4 \\
\hline YP16 & 3 & 2 & 5 & 3 & 4 & 3 & 3 & 4 \\
\hline YP17 & 3 & 3 & 4 & 5 & 2 & 4 & 3 & 4 \\
\hline YP18 & 3 & 4 & 3 & 2 & 2 & 4 & 2 & 2 \\
\hline YP19 & 3 & 3 & 3 & 4 & 4 & 3 & 3 & 4 \\
\hline YP20 & 3 & 3 & 1 & 1 & 3 & 1 & 3 & 4 \\
\hline YP21 & 3 & 4 & 4 & 4 & 3 & 4 & 3 & 4 \\
\hline YP22 & 4 & 3 & 4 & 3 & 4 & 3 & 4 & 3 \\
\hline YP23 & 4 & 3 & 4 & 4 & 4 & 3 & 4 & 4 \\
\hline YP24 & 5 & 4 & 5 & 2 & 3 & 4 & 4 & 3 \\
\hline YP25 & 3 & 3 & 3 & 3 & 3 & 4 & 5 & 4 \\
\hline YP26 & 5 & 2 & 5 & 2 & 3 & 5 & 5 & 4 \\
\hline YP27 & 4 & 3 & 4 & 2 & 4 & 5 & 4 & 4 \\
\hline YP28 & 3 & 4 & 3 & 3 & 3 & 1 & 2 & 3 \\
\hline Total & 100 & 90 & 99 & 94 & 96 & 99 & 105 & 100 \\
\hline Average/YP & 3.6 & 3.2 & 3.5 & 3.4 & 3.4 & 3.5 & 3.8 & 3.6 \\
\hline $\begin{array}{l}\text { No. of YP } \\
\text { with Score } \\
\text { below } 3 \\
\end{array}$ & 2 & 5 & 5 & 7 & 4 & 3 & 3 & 2 \\
\hline \multicolumn{9}{|l|}{ Legends: } \\
\hline \multicolumn{4}{|c|}{ A: Client Status } & \multicolumn{5}{|c|}{ E: Personal Need Assessment } \\
\hline \multicolumn{4}{|c|}{ B: Rights \& Obligations } & \multicolumn{5}{|c|}{ F: Setting of Working Goals } \\
\hline \multicolumn{4}{|c|}{ C: Personal Records } & \multicolumn{5}{|c|}{ G: Feedback on Helping Process } \\
\hline \multicolumn{4}{|c|}{ D: Worker's Intervention Plan } & \multicolumn{5}{|c|}{$\begin{array}{l}\text { Meaning of Score: } 1=\text { Very Poor; } 2 \text { = Poor; } \\
3=\text { Fair; } 4 \text { = Good; } 5 \text { = Very Good }\end{array}$} \\
\hline
\end{tabular}

